необходимой для преобразования действительности. В широкой сфере евразийства пристально рассматривались вопросы культуры. В трудах религиозного философа, протоиерея Георгия Флоровского (1893-1979), философа, историка, поэта Льва Петровича Карсавина (1882-1952), философа и публициста князя Николая Сергеевича Трубецкого (1890-1938) ставились самые высшие задачи духовного содержания и идеального предназначения человека. Большие идеи евразийской концепции в части поиска гармоничного равновесия и симфонического содержания человеческой личности, отказ трактовать человека как машину потребления и наслаждения крайне актуальны для современности.

\section{Список литературы}

1. Лихачёв Д. С. О «неточности» искусства и несколько мыслей о стилистических направлениях // Очерки по философии художественного творчества. Санкт-Петербург, 1999. С. 59-73.

2. Лихачёв Д. С. Искусство памяти и память искусства // Критика и время. Ленинград, 1984. C. $68-74$.

3. Репина C. Метаморфозы Олега Кулика. URL: https://daily.afisha.ru/archive/gorod/archive/oleg_kylik/ (5.02.2018).

Marina V. Moscaluk, Doctor of Art Criticism, Professor, Krasnoyarsk State Institute of Arts (Krasnoyarsk, Russia) mawam@rambler.ru

\title{
CHALLENGES OF GLOBALIZATION IN THE EURASIAN SPACE: ART AND NON-ART
}

Summary. The paper focuses on some extremely negative consequences of cultural globalization process, such as the mass culture's aggressive expansion, elimination of ethnic cultural systems, public tolerance to ideas of moral nihilism that are outspreaded in a format of ethically disputable cultural events. The author re-arises a question about borders of creative freedom of an ethically indifferent artist whose artistic language consciously ignores the distinguishing the kindness and the evil, as well as hierarchy in "high" and "low" genres of art.

The author argues a need of elaborating compromise version of assessment criteria for work of artistic creativity whereby it is possible to distinguish the true masterpiece with doubtless aesthetical value from mass culture production. A work of contemporary art, in the author's opinion, cannot be positively or negatively rated quickly and reliably but essential condition for its value definition for culture should be accordance of its form with high-level of its performance because work of art that does not meet the aesthetics criteria is leaved behind the edges of art world. The author notes that an artist's creative progress is impossible without his or her in-depth knowledge of motherland's precious spiritual and artistic experiences. On this count, the author's viewpoint is close to the Eurasianists' standpoint concerning cultural and aesthetics questions.

Keywords: cultural globalization, the Eurasian space, worldview values, borders of an artist's creative freedom, ethic cultural traditions.

\section{References}

1. Likhachov D. S. O «netochnosti» iskusstva i neskol'ko myslej o stilisticheskih napravleniyah [On "Inaccuracy" of the Art and Some Thoughts About Stylistic Directions]// Ocherki po filosofii hudozhestvennogo tvorchestva [Essays on Philosophy of Artistic Creativity]. Saint-Petersburg, 1999. Pp. 59-73.

2. Likhachov D. S. Iskusstvo pamyati i pamyat' iskusstva [Art of Memory and Memory of Art] // Kritika i vremya [Criticism and the Time]. Leningrad, 1984. Pp. 68-74.

3. Repina S. Metamorfozy Olega Kulika [Oleg Kulik's Metamorphoses]. URL: https://daily.afisha.ru /archive/gorod/archive/oleg_kylik/ (5.02.2018).

\section{ИСКУССТВОВЕДЧЕСКИЕ ПОДХОДЫ В ИЗУЧЕНИИ КОМПЛЕКСОВ ПЕТРОГЛИФОВ: ОПЫТ СЕМАТИЧЕСКОГО АНАЛИЗА КОМПОЗИЦИИ «ШАМАН НА ВОЛКЕ» В БАГА-УЙГУР В ЗАПАДНОЙ МОНГОЛИИ}

Аннотация. На примере крупнейшего комплекса петроглифов в Бага-Уйгур I в Западной Монголии автор статьи исследует значимые для искусствоведения вопросы: как выглядел художник в древности с точки зрения художественных задач, какими материалами и инструментами он пользовался, какова была его система средств 
художественной выразительности. Статья содержит искусствоведческое и культурологическое описание композиции петроглифов из комплекса Бага-Уйгур I.

Ключевые слова: Западная Монголия, Бага-Уйгур I, петроглиф, художник, шаман.

Исследования последних двух десятилетий по петроглифам в трансграничной области на Алтае, на территории Республики Алтай, западных аймаков в Монголии, на северо-западе Китая и в ВосточноКазахстанской области Республики Казахстан, упрочили мнение о том, что эта территория может рассматриваться как один из крупнейших центров сосредоточения искусства древних культур. Стараниями археологов и историков уже описаны и введены в научный оборот комплексы в Западной Монголии и в Республике Алтай в России. Здесь располагаются крупнейшие комплексы петроглифов не только в Монголии, но и в мире, получившие название по месту расположения Бага-Уйгур и Цагаан-Сала.

О мировом значении этих комплексов можно говорить без преувеличения: во-первых, они поражают своими масштабами - практически непрерывная лента петроглифов тянется вдоль долины реки Бага-Ойгур на протяжении более 15 километров. Но не только количеством, но и замечательными художественными качествами многих отдельных изображений и композиций эти места, вне всякого сомнения, должны привлечь внимание не только историков и археологов, но и этнографов, антропологов, культурологов и, конечно, искусствоведов. По сути дела, это огромный музей под открытым небом, хранящий еще немало загадок и образов выдающегося художественного значения. Подчёркивая значимость памятника, стоит сказать, что комплексы петроглифов Цагаан-Сала, Бага-Уйгур, приуроченные к ним ШиветХайрхан, Арал Толгой уже внесены в список Всемирного культурного наследия ЮНЕСКО.

Огромный вклад в основательное изучение этих комплексов и продвижение в Список Всемирного наследия ЮНЕСКО сделала международная экспедиция, в ядро которой входили Э. Якобсон, В. Д. Кубарев, Д. Цэвээндорж. Их многолетняя работа нашла свое отражение в многочисленных публикациях и фундаментальной монографии [1], к которой мы не раз обратимся ниже.

Исследования нашей российско-монгольской искусствоведческой экспедиции, которую с монгольской стороны возглавляла профессор, кандидат искусствоведения, директор института искусств и дизайна Монгольского государственного университета культуры Д. Уранчимэг, а с российской стороны, - автор настоящей статьи, велись на протяжении десяти лет по этим и другим комплексам петроглифов в России, на территории Республики Алтай. Собранный материал - описание и фотофиксация сотен уникальных по своим художественным и семантическим особенностям композиций - вдохновляет на исследования и уже помог в прояснении ряда важных вопросов с искусствоведческой точки зрения.
Во-первых, удалось проследить, как наследие прошлого повлияло на современный художественный процесс в Сибири и Монголии. Можно смело утверждать, что петроглифы, изваяния, каменные сооружения дали мощный толчок в формировании нового стиля в искусстве, который предложено назвать «метаисторический экспрессионизм» [2, с. 208-212]. Художники этого стиля не цитируют искусство прошлого, а творчески его осмысливают. В процессе погружения в материал они приходят к ярким открытиям, через (мета) историческое наследие они стремятся отобразить образы эйдетической реальности, что некогда были открыты их далекими «коллегами» из каменного и бронзового века. Это замыкание наследия прошлого с современной художественной культурой - само по себе выдающееся явление, которое еще требует основательного анализа.

Была замечена и кросс-культурная перекличка на уровне общих сюжетов с отдаленными от трансграничной области на Алтае регионами, например, с петроглифами Северной Индии [3, с. 258-264]. Поставлены и волнующие, чисто искусствоведческие вопросы: как выглядел художник прошлого, естественно, не в модусе его внешности, а с точки зрения художественных задач - кто учил мастера, каковы были его инструменты, краски, сюжеты, система средств художественной выразительности и т. д. Поскольку творческий процесс хоть в его современном виде, хоть и в отдаленном прошлом, должен быть схожим, то легко предположить следующее. Как и сегодня, не все люди художественно одарены, а среди художественно одаренных есть наиболее талантливые, которые становятся выдающимися мастерами не только благодаря своим способностям и постоянному кропотливому труду, но и благодаря помощи учителя. Порой общение, даже краткое, с талантливым опытным художником радикально меняет все в жизни и творчестве художника. Это сегодня, а разве в прошлом могло быть иначе? По ряду признаков, можно выдвинуть гипотезу, что были творческие группы, наподобие возрожденческих боттег, где вокруг одного или нескольких мастеров формировалась школа подмастерьев, которые шаг за шагом овладевали секретами мастерства. Но не только. Уже выделен круг так называемых канонических сюжетов, восходящих к древнейшим пластам мифопоэтики, например, солярный олень. Эти образы широко распространены по всей трансграничной области на Алтае. Порой кажется, что они выполнены по одному трафарету, с поразительным сходством. Это значит, что перед нами, как говорят искусствоведы, одна рука, или один мастер, но вернее всего это школа, которая могла на протяжении многих веков хранить и воспроизводить канонические образы. И, главное, члены этого сообщества 
знали и следовали религиозным представлениям, присущим тем культурам. Только ли знали и воспроизводили эти образы древние мастера или сами были носителями культа, соединяя в себе художника и шамана, этот вопрос остается открытым. Но по аналогии с описаниями современных ученых (Т. Фрезер, А. Голан, Леви Брюль и др.), все шаманы в традиционных обществах были художественно одарёнными людьми и это хорошо видно на примерах бубнов, костюмов и других атрибутов шаманского культа. Поэтому предположение о сочетании художника и шамана в одном лице небеспочвенно, но требует своего исследования.

К чисто искусствоведческим относятся и вопросы: какими средствами и материалами были получены те или иные изображения. Исследования, проведенные археологами, приоткрывают многие тонкости в этом вопросе [4, с. 187-201; 5]. Они все учитываются в наших исследованиях. Кроме того, в экспедицию были привлечены профессиональные художников, и беседы с ними и их работа над петроглифами дали повод к новым ракурсам изучения самого художественного процесса.

Мнения художников и новые подходы в изучении петроглифов, в частности, трасология (изучение на микроуровне следов нанесения рисунков) дают основание говорить о том, что мастера прошлого имели разнообразные инструменты нанесения и, как современный художник, должны были иметь и своеобразные палитры, емкости для красок, нечто напоминающее кисти и т. д. Но далее возникает вопрос о том, кто изготавливал эти инструменты, краски и прочее, - все то, что нужно для художественного процесса, все предметы и материалы. Скорее всего, сам мастер, но учитывая трудозатраты и на изготовление инструментов, и на исполнение своих работ, он должен быть практически все время этим занят, а отсюда следует, что он был выделен из общей массы племени, не был задействован или мало задействован в текущих и актуальных для жизни делах. А это говорит о том, что племя признавало значение его работы и поддерживало его. Что говорит о высоком статусе художника прошлого.

Наконец, в числе искусствоведческих вопросов есть такие, как: где подготовительные рисунки, где этюды и прочие вспомогательные материалы. Разумеется, найти этюды бронзового века невозможно, но среди тысяч рисунков в том же Цагаан-Сала и БагаУйгур находятся рисунки, явно начатые и не завершенные. Более того, можно предположить, что мастер остановил процесс, потому что увидел принципиальную ошибку. Так происходит и ныне, когда художник останавливает или заново переписывает свою картину. Художник прошлого не имел холстов, но точно имел краски. Микрофотографирование показало, что прежде чем начиналась пробивка инструментом контура, прочерчивался рисунок остро оточенным резцом. По штриху и шла насечка, и, что особенно ценно, были обнаружены сбивки от уверен- но прочерченной линии. Что это было - ошибка мастера, неуверенная рука подмастерья, изменение творческой задачи, - трудно сказать. Важно отметить близость художественного процесса прошлого и настоящего. То, что подготовительные работы велись, не вызывает сомнения. Искусствоведы и художники часто поражаются идеальному вписыванию в плоскость камня той или иной композиции. Это прямо говорит об уровне одаренности, о чувстве художественного вкуса и пропорциональности, которыми были наделены мастера прошлого. Но даже самый одаренный мастер ныне, прежде чем начнет свою работу, постарается сделать хотя бы быстрый набросок, который поможет вписать изображение в границы плоскости. Это должно было быть и в прошлом, ведь поправить рисунок, переписать на камне невозможно. Тем более что дополнительного свободного камня с такой плоскостью, твёрдостью, фактурой поверхности может просто не быть. Нужно учитывать и то, что выбор место расположения крупных композиций прямо говорит о включении изображения в религиозный обряд, который требовал ориентации по сторонам света, свободного пространства рядом и т. д. Все эти ограничения должны были заставлять художника прошлого тщательно подготавливаться к процессу исполнения. Вероятнее всего, красящим веществом наносился предварительный рисунок на камне, а затем уже шла работа по пробивке. Не исключается при этом, что цвет рисунка мог учитываться на других этапах. А, назовем это так, штудии и этюды могли выполняться на других, менее ответственных и выделенных плоскостях. Замечены были композиции, когда художники с более развитой и усовершенствованной художественной культурой делали изображения подле рисунков своих предшественников, изображая сходные сюжеты. Чем же это отличается от соревновательности современных художников?

Анализ средств художественной выразительности в композициях петроглифов - еще слабо разработанная тема в искусствоведении. Мешает многое: высокая степень условности изображения, наслоение разновременных изображений, разумеется, утраты и нерешенность некоторых вопросов. Например, есть основания полагать, что мы видим изображение не в том виде, в котором их видели современники. Единого мнения у археологов о том, были ли расписаны поверх выбивки рисунки или нет, не существует. Относительно выбивки можно заметить разные приемы - глубокая выбивка, протирания поверхностей, прочерчивания и т. д. Можно предположить, что перфорированную поверхность скалы покрывали цветными пастами, и быть может, это защитило рисунки от воздействия солнечных лучей и разного рода осадков. Порой они выглядят, как только что выполненные.

И, самое значимое, что затрудняет возможность искусствоведческой интерпретации, - это сюжетная сторона изображения, непрослеженная связь изображения с другими на этой плоскости и на отдалении 
и сторонами света, невозможность точно реконструировать обряд, в котором участвует то или иное изображение. Выход из всего этого круга вопросов видится в выделении среди всего числа рисунков композиционно завершённых работ, в которых явно начинает просматриваться сюжетная сторона, видны ходы мысли художников для достижения художественной и образной выразительности. Их искусствоведческое и культурологическое описание в итоге может привести к выделению эталонных произведений, и, опираясь на их анализ, фиксируя специфику изображения, стилистику и почерк мастера, можно продвинуться дальше в интерпретации петроглифов и введении их в оборот как произведений искусства.

Продемонстрируем некоторые первичные подходы на примере изучения композиции из комплекса Бага-Уйгур I. Есть основания считать, что это культовое изображение, на котором представлен «шаман» в маске. Рисунок был отмечен исследователями комплекса и воспроизведён, правда фрагментарно, в упомянутой выше монографии Э. Якобсона, В. Д. Кубарева, Д. Цевээндоржа [1, с. 343 , рис. 2]. Фрагментарность воспроизведения не дает возможность представить себе всю композицию в целом и соответственно не позволяет оценить сюжетную сторону (см. рис.).

О том, что это, возможно, культовое изображение, можно говорить не только по характеру и деталям, авторы уже упомянутой книги дают в ней целый раздел, в котором обосновывают сакрально-ритуальный характер многих изображений $[1$, с. 37-42].

Важное значение имеет не только композиция, но и камень. Это отдельно лежащий валун, с достаточно большим свободным пространством вокруг, что позволяет предположить проведение вокруг него разного рода обрядов, например танцев и хороводов. Форма камня удобна для жертвоприношения, основная плоскость с шаманом ориентирована на южную сторону, которая имеет сакральный статус, что подтверждается и многими другими археологическими и этнографическими примерами, например, вход в юрту ориентирован на южную сторону.

Главное в композиции - это фигура «шамана», которая стоит на фигуре волка. К морде животного примыкают (как будто бы обнюхиваются, вдыхают запах друг друга) морды других хищников, по явным признакам барс и собака. Это явно ритуальная сцена, потому что и стоять на спине волка, и тем более так близко сопри- касаться друг с другом в жизни эти животные не могут. Масштаб фигур шамана и хищников говорит о том, что это громадные - исключительные, не реальные животные, которые собой должны олицетворять особые мощные силы. Стояние на спине волка и замыкание фигур животных говорят об их подчинении «шаману», который явно возвышается над силами природы, покоряя их себе.

Легко заметить продуманный характер изображения. Фигура «шамана» возвышается над фигурой волка. У него характерный волчий по форме хвост, у собаки он акцентирован завитком на спину. Тяжёлая, лобастая морда и, на что хотелось бы обратить внимание, отвислый живот. Это не характерно для поджарых и подвижных хищников, и, быть может, здесь изображён не волк, а волчица, ожидающая детенышей, а это дает возможность привлечения большого числа сюжетов из мифопоэтики.

Волк - один ведущих типов евразийской мифологии. С глубокой древности люди высоко оценивали способности волка к организованным загонным охотам, а быть может, и учились у них чутью, скорости
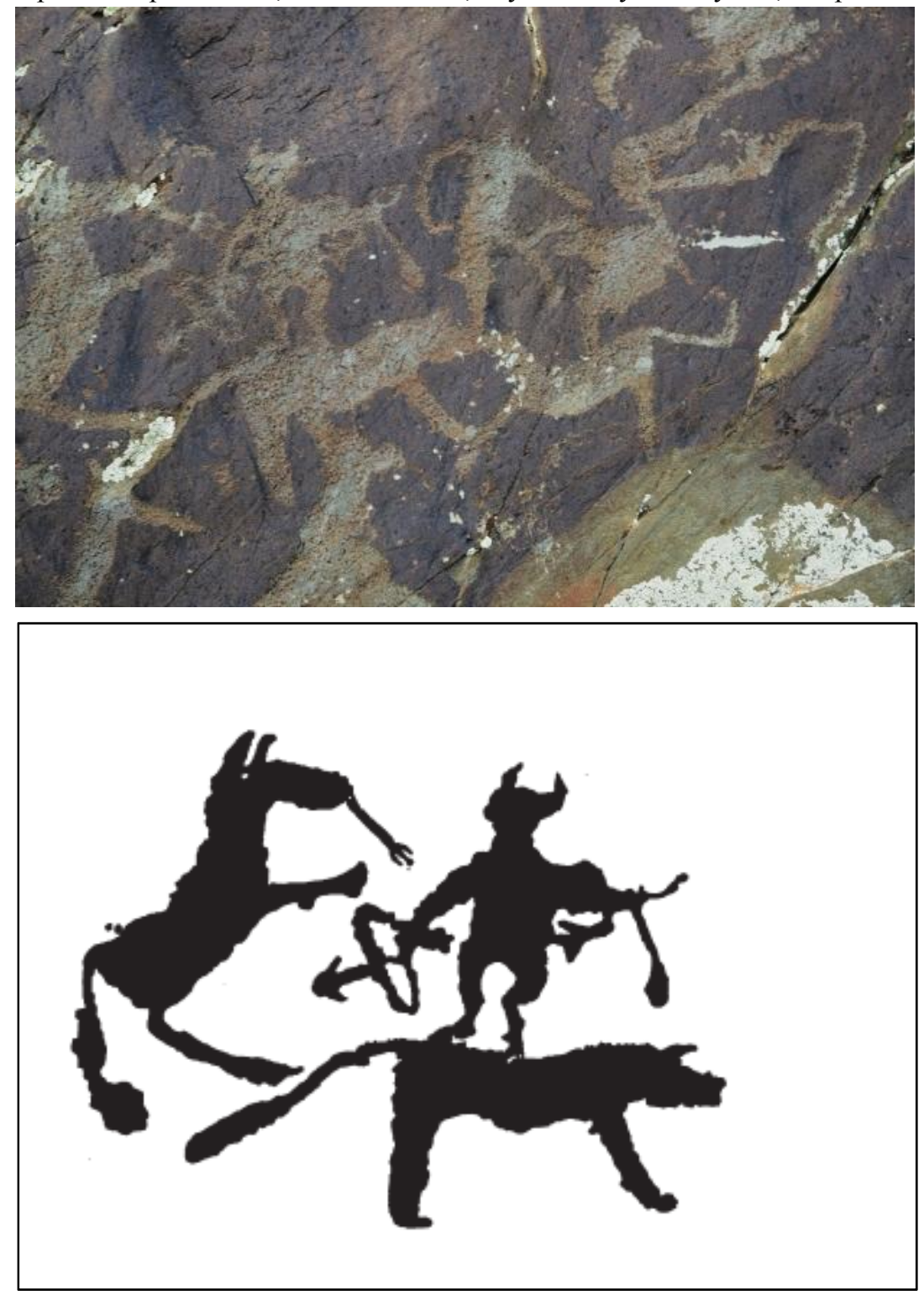
движения, преданности и заботе о потомстве. Волк сакрализован в тюркской культуре - легенда гласит, что тюрки произошли от волчицы, то же самое можно встретить у монголов и других народов. Конечно, и в бронзовом веке волк был включен в пантеон божественных животных и был тотемом многих племен, о чем говорят находки в курганах и изображения в петроглифах. Волк, безусловно, был доминирующим животным в данной долине Цагаан-Сала и Бага-Ойгур. То, что шаман возвышается над волчьей фигурой, значит момент подчинения его своей воле и силе.

У барса своя миссия. Он также герой многих мифов, его описывают как владетеля и пастуха горных баранов, и встречаются композиции, где он возвышается над фигурами баранов. Есть мифы, которые говорят о происхождении отдельных родов от барса, он также включён в число тотемных животных для многих народов. Была подмечена одна особенность древних охотников в поведении барса: он бросается на свою жертву сверху. Это всегда бывает неожиданно, и бросок очень точный и сильный. В этом моменте важно отметить нападение сверху, то есть барс - это сила сверху, в определённом смысле сила небес. Неслучайно в скифской культуре сформируется образ крылатого барса.

Высшее, небесное позиционирование барса подтверждается и другими композициями. Например, в известном комплексе Калбак-Таш на территории Республики Алтай химера, по виду явно схожая с барсом, бросается на людей сверху, для чего очень удачно использован покатый склон скального выступа. Подобного рода композиция с нападением барса на человека в похожем, как и на Калбак-Таше, грибовидном головном уборе зафиксирована и в ШивээтХайрхан (Монголия). Биологи утверждают, что нападение барса на человека - это исключительное событие, более того, снежный барс легко приручался, и есть древние изображения с совместными охотами людей и барсов. Поэтому, за изображением стоит, скорее всего, олицетворение сил небесного порядка.

Логично вывести, что собака, третий персонаж в этой композиции, - олицетворение подземных сил. Что хорошо известно по евразийской мифологии, ярким воплощением здесь можно считать трехголового пса Цербера.

Таким образом, все три уровня и соответственно все стихии, с ними связанные, сведены вместе, замыкаются мордами животных, а над ними возвышается фигура шамана. Остановимся на нем подробнее. В его руках, просматриваются два предмета - лук со стрелой и дубинка. На голове маска с явными признаками рогов, и при хорошем увеличении читается морда животного, скорее всего, быка. Бык, дубинка и лук со стрелой могут быть интерпретированы в качестве атрибутивных признаков божества громовника. Миф о нем широко распро- странён в данном регионе. Г. Потанин посвящает этому образу божества грома - Тэнгри-хану развернутое культурологическое исследование [6, с. 116167]. Другими словами, перед нами, возможно, высшее божество небесного плана, которое подчиняет себе все силы природы. Маска и костюм быка только дополняют этот образ, который связан с небесным быком, дождем и громом.

Все рядом расположенные фигуры требуют специального и подробного рассмотрения. По характеру насечки и стилевым признакам можно говорить, что все они выполнены в один период в бронзовом веке. Видимо, связан с главной фигурой и образ лошади, возвышающейся слева от главных персонажей. От нее к богу-громовнику ведет линия - может быть, симоволическое изображение повода. Конечно же, требуется более детальное изучение этой композиции и культуролого-семантический анализ всего объекта в целом, но, как показывает даже первичный подход, памятник может сообщить очень много интересного и ценного для постижения внутреннего мира древних народов. Очевидно и то, что подобного рода интерпретации позволяют ввести данную композицию в число эталонных произведений искусства в комплексах петроглифов.

\section{Список литературы}

1. Кубарев В. Д., Цэвээндорж Д., Якобсон Э. Петроглифы Цагаан-Салаа и Бага-Ойгура (Монгольский Алтай). Новосибирск, 2005. 640 с.

2. Шишин М. Ю. Основные черты стиля «метаисторический экспрессионизм» и его проявление в искусстве современных художников Сибири и Монголии // Исторические, философские, политические и юридические науки, культурология и искусствоведение. Вопросы теории и практики. 2017. № 11. С. 208-212.

3. Белокурова С. М., Ом Ч.Х., Шишин М. Ю. Петроглифы Алтая и Гималаев: общее и особенное, подходы к искусствоведческому анализу // Исторические, философские, политические и юридические науки, культурология и искусствоведение. Вопросы теории и практики. 2017. № 12-5. С. 258-264.

4. Дэвлет Е. Г., Гиря Е. Ю. «Изобразительный пласт» в наскальном искусстве и исследования техники выполнения петроглифов Северной Евразии // Древнее искусство в зеркале археологии. К 70-летию Д. Г. Савинова. Кемерово, 2011. С. 187-201.

5. Дэвлет Е. Г. Памятники наскального искусства: изучение, сохранение, использование. Москва, 2002. URL: http://arheologija.ru/devlet-pamyatnikinaskalnogo-iskusstva-izuchenie-sohranenie-ispolzovanie/ (20.03.2018).

6. Потанин Г. Громовник в повериях и сказаниях племен Южной Сибири и Северной Монголии // Журнал Министерства народного просвещения. 1882. Ч. ССXIX. С. 116-167. 
Mikhail U. Shishin, Doctor of Philosophical Sciences, Professor

Polzunov Altai State Technical University (Barnaul, Russia)

shishinm@gmail.com

\section{PETROGLYPHS COMPLEXES FROM THE VIEWPOINT OF ART HISTORY: SEMANTIC INTERPRETATION OF "THE SHAMAN RIDING THE WOLF", THE PETROGLYPHS COMPOSITION (BAGA-UYGHUR, WESTERN MONGOLIA)}

Summary. Studying of petroglyphs located in Western aimaks (a territorial unit) of Mongolia assured the researches that the region is one of the biggest centers of the ancient cultures' art. Baga Uyghur (Oigor) and Tsagaan Sala, the petroglyphs complexes with the world significance, entered in the UNESCO World Heritage List.

A major contribution to researching the petroglyphs complexes was made by the international expedition with Ester Yakobson, Vladimir Kubarev, Dadmii Tseveendor$\mathrm{dzh}$ as its core. Results of the expedition have been outlined in "Petroglyphs of Tsagaan Sala and Baga Uyghur (the Mongolian Altai)" (Novosibirsk, 2005), the multi-authored scientific monography. Studying of the petroglyphs was conducted for ten years by team of Russian and Mongolian specialists headed by D. Uranchimeg and Mikhail Shishin. Collected material helped to clear up a whole host of issues raised by the art history. For example, it is managed to trace an influence of the ancient cultural heritage to today's Siberian and Mongolian artistic life. In particular, petroglyphs, statues, and stone constructions have given the strong impulse to forming a new artistic style named "metahistorical expressionism".

Also, there was noticed cross-cultural talk in narrative commonality with regions distanced from the trancebordered Altai, for example with petroglyphs from the North India. The author makes a supposition about beingness of ancient creative groups with its master and subworkers who had been practiced in crafts step by step. In particular, the set of so-called "canonic subjects" spread throughout the trancebordered Altai confirms it. The author offers to mark images with finished composition among the rest painted by unknown ancient artists; presents some results of semantic interpretation of the one of these compositions (from Baga Uyghur (Oigor) I, archaeological complex) shows a ritual scene: "shaman" with a horned mask on his face, having a bow and a maul, standing on a wolf's back. A dog with a (snow?) leopard sides with a wolf's jaw. The researcher offers to hold an association between each animal and the upper (a (snow?) leopard), the lower (a dog) and the middle (a wolf) world. In such case, a "shaman" may be understood as Tengri Khan, a higher divinity.

Key words: Western Mongolia, Baga-Uygur I, a petroglyph, an artist, a shaman.

\section{References}

1. Kubarev V.D., Tsehvehehndorzh D., Yakobson E. Petroglify Tsagaan-Salaa i Baga-Ojgura (Mongol'skij
Altaj) [Petroglyphs of Tsagaan Sala and Baga Uyghur (the Mongolian Altai)]. Novosibirsk, 2005. 640 p. [In Russ].

2. Shishin M.Yu. Osnovnye cherty stilya «metaistoricheskij ehkspressionizm» $\mathrm{i}$ ego proyavlenie $\mathrm{V}$ iskusstve sovremennykh khudozhnikov Sibiri i Mongolii [The Key Features of the "Metahistorical Expressionism" Style and Its Displaying in Contemporary Siberian and Mongolian Artists' Works] // Istoricheskie, filosofskie, politicheskie i juridicheskie nauki, kul'turologija i iskusstvovedenie. Voprosy teorii i praktiki [Historical, Philosophical, Political and Law Sciences, Cultural Studies and Art History. Theoretical and Practical Questions]. 2017. No. 11. Pp. 208-212. [In Russ.].

3. Belokurova S. M., Om Ch. Kh, Shishin M. Yu. Petroglify Altaya i Gimalaev: obshhee i osobennoe, podkhody $\mathrm{k}$ iskusstvovedcheskomu analizu [Petroglyphs of the Altai and the Himalayas: the Similarities and the Differences, Approaches to the Analysis from the Point of View of Art History]// Istoricheskie, filosofskie, politicheskie $\mathrm{i}$ juridicheskie nauki, kul'turologija $\mathrm{i}$ iskusstvovedenie. Voprosy teorii i praktiki [Historical, Philosophical, Political and Law Sciences, Cultural Studies and Art History. Theoretical and Practical Questions]. 2017. No. 12-5. Pp. 258-264. [In Russ.].

4. Dehvlet E. G., Girya E. Yu. «Izobrazitel'nyj plast» v naskal'nom iskusstve i issledovaniya tekhniki vypolneniya petroglifov Severnoj Evrazii ["Graphic Layer" in the Rock Art and Research the Painting Technique of Petroglyphs from the Northern Eurasia] // Drevnee iskusstvo v zerkale arheologii. K 70-letiju D. G. Savinova [Ancient Art in the Mirror of Archeology. To Dmitry Savinov $70^{\text {th }}$ Anniversary]. Kemerovo, Pp. 187-201. [In Russ.].

5. Dehvlet E. G. Pamyatniki naskal'nogo iskusstva: izuchenie, sokhranenie, ispol'zovanie [Rock Art Monuments: Study, Preservation, and Usage.] Moscow, 2002. URL: http://arheologija.ru/devlet-pamyatniki-naskalnogoiskusstva-izuchenie-sohranenie-ispolzovanie (20.03.2018). [In Russ.].

6. Potanin G. Gromovnik v poveriyakh i skazaniyakh plemen YUzhnoj Sibiri i Severnoj Mongolii ["Gromovnik" in the Southern Siberian and Northern Mongolian Tribes' Legends and Folk Tales]// Zhurnal Ministerstva narodnogo prosveshhenija [Journal of the Ministry of Education]. 1882. Pt. CCXIX. Pp. 116-167. [In Russ.]. 